\title{
CONVERGÊNCIA ENTRE ESCRITA E IMAGEM NO REGISTRO ESCRITO DO ESTÁGIO SUPERVISIONADO NO CURSO DE LETRAS
}

\section{CONVERGENCE BETWEEN WRITING AND IMAGE IN THE WRITTEN RECORD OF THE SUPERVISED INTERNSHIP IN THE LANGUAGE COURSE}

Luana Clementino Chalegre*

\begin{abstract}
RESUMO: Este artigo visa analisar a convergência entre a imagem e o registro escrito feito pelo aluno-pesquisador (estagiário) durante o estágio supervisionado do curso de Letras. Para verificar como esses escritos podem se transformar em imagens, contaremos com os contos "A aventura de um fotógrafo" e "A aventura de um míope", da obra "Os amores difíceis" (CALVINO, 1992). Tendo em vista que a escrita de Calvino parte da imagem, podemos pensar que os registros feitos ao longo do estágio supervisionado também partem de uma série de imagens. É importante este estudo, pois geralmente encontramos trabalhos sobre estágio a partir de perspectivas procedimentais, para esse estudo, partiremos das premissas dos contos de Calvino, que é um autor no sentido strictu do termo, que o aluno-pesquisador, no sentido da autoria, ocupa a mesma posição partindo das imagens coletadas em sala de aula. $O$ problema sabido ao longo do estágio é a dificuldade em se trazer por escrito o que é observado e ser dada a devida importância ao processo de coleta e registro de sala de aula. Além do mais, as inúmeras possibilidades proporcionadas sobre o que é vivenciado em sala de aula, extrapolando muitas vezes áreas diferentes da formação do estudante, desde que este esteja disposto a ver. Observaremos como essas ações vivenciadas podem ser vistas imageticamente, decalcando os registros escritos em fotografias da sala de aula; para isso, contaremos com as ideias de Blikstein (2018) e Cortázar (1974), refletindo sobre a técnica de escritura elaborada pelo alunopesquisador.
\end{abstract}

Palavras-chave: Escrita; Imagem; Ensino superior; Estágio.

ABSTRACT: This article aims to analyze the convergence between the image and the written record made by the student-researcher (intern) during the supervised internship of the Language course. In order to verify how these writings can be transformed into images, we will count on the short stories "The adventure of a photographer" and "The adventure of a nearsighted", from the work "The Difficult Loves" (CALVINO, 1992). Considering that Calvino's writing starts from the image, we can think that the records made during the supervised internship also start from a series of images. This study is important, as we usually find work on internship from procedural perspectives, for this

* Mestra em Letras pela USP. Contato: luanachalegre@hotmail.com 
study, we will start from the premises of the tales of Calvino, who is an author in the strict sense of the term, that the student-researcher, in the sense of authorship, occupies the same position starting from the images collected in the classroom. The problem known throughout the internship is the difficulty in bringing in writing what is observed and giving due importance to the classroom collection and registration process. Furthermore, the countless possibilities provided for what is experienced in the classroom, often extrapolating different areas of the student's education, as long as the student is willing to see. We will observe how these experienced actions can be seen imagetically, tracing the written records in classroom photographs; for this, we will rely on the ideas of Blikstein (2018) and Cortázar (1974), reflecting on the writing technique developed by the student-researcher.

Keywords: Writing; Image; Higher education; Internship.

\section{INTRODUÇÃO}

Este artigo se insere no projeto "Leitura e escrita no Brasil, Honduras, Angola e Chile: formação na universidade contemporânea e (re)produção de conhecimento" (Chamada Universal MCTI/CNPq № 28/2018), que articula dois eixos de investigação:

a) as características da leitura e da escrita produzidas por alunos de graduação e pós-graduação ao responderem as exigências de produção postas pelo contexto universitário;

b) a relação entre formação, aprendizado da leitura e da escrita e produção de conhecimento na área de formação desses sujeitos.

A partir de tais eixos podemos refletir como se dá o processo de leitura e escrita ensinado nas universidades para a produção de conhecimento em diferentes áreas formativas do sujeito que a produz. Para o presente trabalho, focaremos o processo formativo no que tange ao estágio supervisionado no curso de Letras na Universidade de São Paulo.

O presente trabalho analisou a escrita nos diários e relatórios de estágio das disciplinas de Metodologia do Ensino de Língua Portuguesa I e II, elaborados 
por alunos de graduação do curso de Letras da Universidade de São Paulo. Todavia, para o presente estudo, elegemos dois fragmentos de um dos diários e relatórios estudados, destacando os pontos que o processo imagético se torna aparente no processo da formalização escrita do contexto observado, tendo à luz o conhecimento adquirido no curso de Metodologia do Ensino de Língua Portuguesa I e II.

Quando refletirmos acerca dos registros escritos no estágio supervisionado, os contos selecionados de Calvino são relevantes como referência para a realização das análises dos fragmentos retirados dos registros do estágio supervisionado, pois ele transforma de modo magistral a imagem em palavra nos contos "A aventura de um fotógrafo" e "A aventura de um míope". O escritor italiano traz a particularidade do "ver", por meio de suas personagens centrais.

Esse "ver", trabalhado por Calvino em seus contos, possibilita refletirmos sobre um problema pungente no estágio: dificuldade em se trazer por escrito 0 que é observado e ser dada a devida importância ao processo de coleta e registro dos eventos ocorridos em sala de aula.

Para o presente estudo, tomo por imagem o registro da realidade de sala de aula feito pelo aluno-pesquisador, a qual é transformada em referente, conforme propõe Blikstein (2018). Neste caso, os sentidos do alunopesquisador, a partir de sua percepção/cognição, transformam o "real" (o que vê e o que ouve) em referente. No conto "A aventura de um fotógrafo", temos Antonino Paraggi, que, sentindo-se excluído da sociedade, aproxima-se da fotografia de modo a viver apenas em função disso, ao passo que, no conto " $A$ aventura de um míope", a personagem Amilcare Carruga enxerga o mundo de três formas: 1. Quando se percebe míope; 2. Quando está com seus óculos e 3. Quando está sem os seus óculos.

Por outro lado, por meio do diário de estágio no ambiente escolar, temos os dados coletados pelo aluno-pesquisador, com os seus olhos que veem a realidade da sala de aula, elencando acontecimentos de diferentes ordens que

\footnotetext{
1 Os alunos de graduação da Letras tiveram seu ingresso pela Faculdade de Filosofia, Letras e Ciências Humanas (FFLCH-USP), porém as matérias da Licenciatura são cursadas na Faculdade de Educação (FE-USP).
} 
se constituem no ambiente escolar, como o ensino e as relações entre os partícipes.

Calvino potencializa a sua narrativa colocando os acontecimentos em ordem cronológica e detalhando-os - a gradação construída também potencializa a tensão na narrativa. Do mesmo modo é interessante para o alunopesquisador que, ao longo de suas observações, seus registros sejam tecidos sob alguma ordem cronológica dos acontecimentos e tragam o máximo de detalhes ${ }^{2}$ possível, incrementando os seus registros escritos.

Sobre os inúmeros eventos que ocorrem simultaneamente na sala de aula e a ordem cronológica desses acontecimentos, podemos trazer à luz a contribuição de Todorov:

\begin{abstract}
O tempo do discurso é, num certo sentido, um tempo linear, enquanto o tempo da história é pluridimensional. Na história, muitos eventos podem desenrolar-se ao mesmo tempo. Mas o discurso deve obrigatoriamente colocá-los um em seguida a outro; uma figura complexa se encontra projetada sobre uma linha reta. (TODOROV apud NUNES, 2000, p. 27).
\end{abstract}

Ante a impossibilidade de registrar a totalidade dos eventos em sala de aula, cabe ao aluno-pesquisador, com concentração, eleger os acontecimentos e registrar o máximo - e da melhor forma - possível.

\footnotetext{
2 O aluno-pesquisador faz um recorte da realidade observada, de forma que inúmeros acontecimentos ficam de fora do registro. É um recorte do que ele pensa ser relevante mostrar, somado ao pressuposto de que os registros são feitos apenas à mão, impossibilitando que seja captado tudo. Nós, seres humanos, temos limitações físicas e mnemônicas que nos impedem de registrar os fatos como fazem a filmadora e o gravador de voz. Além do mais, o uso de uma filmadora, que capta imagem e som, provavelmente causaria um certo incômodo na comunidade escolar e inibiria o comportamento espontâneo do dia a dia; não que a presença do alunopesquisador não traga incômodo, todavia é mais rápido "esquecer" a sua presença na sala de aula, ao passo que a presença de uma filmadora deixaria os partícipes em constante estado de alerta em relação a suas atitudes, e o estado de vigilância de quem vem de fora ficaria mais patente. É importante destacarmos, ainda, que apenas a captação de áudio impossibilitaria o registro das reações paraverbais, bem como a descrição física dos partícipes.
} 


\section{MÉTODO DE PESQUISA}

\section{a) Registros do estágio}

Para a realização do levantamento dos dados, contou-se com o banco de dados "Metodologias"3, que armazena e organiza os relatórios e diários selecionados para o presente trabalho. O banco de dados inclui 105 diários e relatórios entre os anos de 2008 a 2018, dos quais 66 são da disciplina de Metodologia do Ensino de Língua Portuguesa I e II e os 39 restantes são de "Metodologia da Linguística I e II".

O relatório de estágio compreende os dados coletados do diário de campo seguidos de reflexões aprofundadas, de acordo com a temática (escrita, leitura, material didático, gramática, ensino, interação nas falas, etc) que cada evento observado, registrado e selecionado para a composição do relatório exige.

Deve-se enfatizar que, no relatório de estágio, não se teoriza sobre todos os dados contidos no diário de campo, em virtude da grande quantidade de temáticas que emergem das observações. Dessa forma, ao redigir o relatório de estágio, o aluno-pesquisador faz um recorte dos dados mais significativos do diário, a partir dos quais poderá refletir e aprofundar discussões teóricas.

O diário de campo ou diário de observação consiste em uma forma de registro de observações de tudo o que é atentado pelo aluno-pesquisador no estágio supervisionado, acompanhadas, idealmente, de comentários e reflexões próprios. Podem-se registrar as atividades realizadas em classe, bem como as interações entre os indivíduos.

\footnotetext{
3 O Banco de Dados "Metodologias" começou a ser construído em março de 2015 durante a Iniciação Científica sob a orientação do Prof. Dr. Valdir Heitor Barzotto. O banco visava armazenar e organizar os relatórios e diários de estágio elaborados pelos alunos do Professor Dr. Valdir Heitor Barzotto, além de servir de material para pesquisas. Foram digitalizados relatórios e diários das disciplinas de "Metodologia da Linguística I e II", "Metodologia do Português I e II" e relatórios do "Programa Ler e Escrever". Todos esses documentos foram digitalizados e disponibilizados no "Drive" do Google na versão PDF.
} 
Os registros devem ser realizados com rigor, abrangendo o processo de ensino de língua portuguesa e o espaço físico e social da sala de aula; dois critérios devem nortear os relatos: objetividade e especificidade, evitando-se juízo de valor e descrições genéricas, os quais colaboram para a deturpação do espaço no qual se faz a pesquisa.

O informante (I5), cujo trabalho foi escolhido, trata-se de aluno já egresso do curso de Letras - Bacharelado e Licenciatura - da Faculdade de Filosofia, Letras e Ciências Humanas (FFLCH) da Universidade de São Paulo (USP). O informante desenvolveu diário e relatório de estágio supervisionado para a disciplina de Metodologia do Ensino de Língua Portuguesa I (MELP I) no ano de 2014.

Os critérios utilizados para escolher os fragmentos dos diários de observação foram: o princípio da informatividade; situações que possam ser observáveis em diversas unidades escolares de diferentes realidades ou situações que possam ser inusitadas em outras escolas; passagens imagéticas aparentes na formalização escrita do contexto observado.

\section{b) Fragmentos selecionados do diário de observação (corpus)}

Vejamos a seguir as duas passagens selecionadas do diário de observação do estágio, a fim de correlacionarmos os eventos do estágio supervisionado às ideias presentes nos contos de Calvino na análise em item próprio.

O fragmento 83 se dá a partir da interação entre a professora e alunos, a qual trabalhava atividades do livro didático com uma turma de $8^{\circ}$ ano sobre 0 poema "Amor" de Paulo Leminski.

\footnotetext{
a) Fragmento 83

Professora: "Quantas estrofes tem, gente?" [iniciação]

Classe: "Nove." [resposta]

Professora: "NÃO é verso gente." [avaliação]

Classe: "Três." [resposta retificada]

Professora: "Onde vocês estão vendo 3 estrofes, pelo amor de DEUS!" (pausa breve) "Eu expliquei na aula passada. Estrofe é um conjunto de versos, tem um espaço que separa!" [avaliação]
} 
Regina4: "Não entendi nada."

Professora: "Você nunca entende nada..." e continuou "Obrigação de quem falta é pegar a matéria!"

$\left(\right.$ I5 MELP1 2014 F83 D) ${ }^{5}$

No fragmento 21, temos a interação da professora com alguns alunos de uma turma de $8^{\circ}$ ano. A professora tentava fazer a chamada com o tablet da escola, contudo, parecia ter dificuldade, pois o sistema e a internet não funcionavam bem.

b) Fragmento 21

Aluno1: "Professora, pode levar pra casa?" (Referindo-se ao tablet)

Aluna: "Se fosse eu,] Eu robava"

Professora: "Se eu roubar, vou presa"

Aluno1: "Pelo menos, você vai ficar com o tablet"

(I5 MELP1 2014 F21 D) $)^{6}$

\section{c) Obra de Calvino}

Ítalo Calvino (1923-1985) em "Os amores difíceis" (Gli amori difficili - 1970) reúne 15 contos, escritos entre 1949 e 1967, dividindo o livro em duas partes (Os amores difíceis e A vida difícil).

$\mathrm{Na}$ obra, o autor traz situações cotidianas, narradas de forma inquietante, levando-as ao extremo por meio da linguagem e da literatura. Calvino explora a complexidade da vida em seu interior em contos de amor e solidão misturando ilusão e realidade.

Os textos realistas com carga fabulística (realismo fantástico) exigem tempo para a sua "digestão", pois o desassossego instalado ao final de cada conto desponta a percepção de um certo vazio que circunda as relações humanas, revelando-nos que há espaços que não são preenchidos, por mais que nos esforcemos em transmitir alguma mensagem ao outro. De modo que fica em evidência na base de muitas das histórias a dificuldade de comunicação e a zona de silêncio no fundo das relações humanas.

\footnotetext{
${ }^{4}$ Nome fictício.

5 A sigla corresponde a: Informante 5 da disciplina de Metodologia do Ensino de Língua Portuguesa 1, no ano de 2014, fragmento 83 do Diário de Observação.

${ }^{6}$ A sigla corresponde a: Informante 5 da disciplina de Metodologia do Ensino de Língua Portuguesa 1, no ano de 2014, fragmento 21 do Diário de Observação.
} 


\section{d) Contos selecionados de Calvino}

Para o presente estudo, que pretende compreender o registro do estágio como convergência entre escrita e imagem, além dos dois fragmentos retirados de um diário de observação apresentados no item "b" (fragmentos 83 e 21), contaremos com dois contos, "A aventura de um míope" e "A aventura de um fotógrafo", do livro "Amores Difíceis" de Ítalo Calvino, os quais tematizam as relações concretas de onde o mundo da vida fala para nós via linguagem e fotografia/imagem e servirão de base para a análise dos dados do estágio.

No conto "A aventura de um míope" temos como personagem central Amilcare, para o qual a vida parecia ter perdido o gosto, pois as coisas não tinham a mesma graça de antes. Até perceber que estava míope e o oculista lhe receitou um par de óculos. "A partir daquele momento sua vida mudou, tornouse cem vezes mais rica em interesse do que antes" (p. 88). A possibilidade de enxergar bem novamente o colocou em contato com novos estímulos e o tornou sensível a novas interações com seu entorno.

Esta mudança levou Amilcare a novas aprendizagens, percebendo que é impossível - e eventualmente, indesejável - responder a todos os estímulos do mundo ao nosso redor e mais difícil é agir efetivamente sobre o ambiente, aprendendo a discriminar o que é útil e o que não é.

No conto "A aventura de um fotógrafo" temos como personagem central Antonino Paraggi, o qual vive um crescente isolamento social devido a sua condição de não fotógrafo. Ao longo da narrativa, a personagem imerge progressivamente no mundo da fotografia em seu círculo social, fazendo com que se questione sobre a essência do homem fotográfico.

Antonino Paraggi no que tange à fotografia preocupa-se com a recusa de viver o presente como lembrança futura, crítica que elabora àquelas pessoas que saem de casa para se fotografar e aguardam ansiosas pela revelação das imagens, e somente quando têm as fotos em mãos parecem tomar posse tangível do dia passado. 
É importante destacar que ao longo da narrativa Antonino Paraggi se relaciona com Bice, porém o relacionamento chega ao fim. Antonino cai numa crise e compulsivamente passa a fotografar a ausência de Bice.

Este conto possibilita profundas reflexões no leitor contemporâneo, pois, embora seja um conto de 1955, Calvino parece escrever em nossos tempos, visto que nossa sociedade é fortemente marcada pela fixação (e disseminação) de imagem.

\section{e) Intersecção dos registros de estágio e dos contos de Calvino}

Serão identificados os pontos de confluência entre escrita e imagem nos registros escritos do estágio supervisionado e as imagens que emergem desses registros (fragmentos 83 e 21 - item b "Método de Pesquisa"). Para auxiliar na identificação dessa convergência, contaremos com a tradição literária do autor Ítalo Calvino e, dentro da extensão da sua obra, com os contos "A aventura de um fotógrafo" e "A aventura de um míope", do livro "Os Amores Difíceis".

Pretende-se, então, conceituar e compreender as relações entre linguagem e imagem/ fotografia, como interrogações que tematizam o mundo da sala aula por meio do olhar do aluno-pesquisador. Calvino de modo magnificente faz com que seus escritos se propaguem em imagens e o registro do alunopesquisador pode repercutir em imagem. A partir disso, pinçaremos a ideia de que a leitura e a escrita exigem um saber dialogar com os outros sujeitos/discursos/textos.

Neste ponto, temos recorte de quem escreve o presente artigo, do mesmo modo como o estagiário que faz o recorte da realidade para fazer o registro escrito. Destacamos que os recortes (escolha dos fragmentos e contos, bem como os registros feitos nos diários de observação) buscam manter o necessário distanciamento que requer o trabalho científico e esse distanciamento não é sinônimo de neutralidade, mas de preservação do o rigor à pesquisa/ ao trabalho.

Tendo em vista os contos selecionados de Calvino e a experiência do aluno-pesquisador, optamos por escolher a fotografia como testemunho visual. Além disso, a fotografia trata de um texto híbrido entre imagem e narração. Por 
meio dos registros e da fotografia, o aluno-pesquisador, bem como a personagem de Calvino, Antonino Paraggio, fixa um tempo passado 7 e reconta a história no presente.

Neste processo, a escrita explica os espaços difíceis de explicar, seja nos contos ou nos registros do diário; e a fotografia emana como a possibilidade de visualizar as imagens dos acontecimentos, por isso a junção escrita-fotografia, para que a imagem funcione.

\section{ABORDAGEM TEÓRICA E ANÁLISE DO CORPUS}

Os contos "A aventura de um míope" e "A aventura de um fotógrafo" vão ao encontro dos registros feitos ao longo do estágio supervisionado, pois revelam uma percepção multifacetada da realidade. Nos registros do estágio supervisionado, cada aluno-pesquisador anota ao seu modo os acontecimentos (valorizando alguns eventos e não outros); independentemente das orientações prévias estabelecidas pelo professor da disciplina de estágio, isso ocorre em virtude do filtro do "eu".

Para Calvino traduzir imagens e enunciados em escritos trata-se de uma técnica, a qual é compartilhada pelo aluno-pesquisador em seus registros, contudo, ao longo do processo de escrita dos registros, o estagiário se depara com inúmeras barreiras: criatividade, método, mnemotécnica, tempo, velocidade dos acontecimentos, etc.

Por meio da análise dos fragmentos do diário escolhido e dos contos selecionados de Calvino, procurou-se verificar como a realidade descrita pode ser comparada à fotografia, e podemos reprojetar essa realidade em imagens.

Os registros escritos feitos pelo aluno-pesquisador, podem ser projetados em imagens, as quais possibilitam ao leitor dos diários e dos relatórios de estágio que vivencie a experiência do aluno-pesquisador em sala de aula. Ou seja, temse uma série de acontecimentos que são traduzidos/projetados para o registro

\footnotetext{
${ }^{7}$ Essa fixação ocorre por meio da lente objetiva de uma câmera fotográfica e pelo olhar objetivo do pesquisador; esses olhares são marcados pelas experiências do fotógrafo e do pesquisador.
} 
escrito, neste caso, o diário de observação, o qual reprojetaremos em imagens no presente trabalho. Vejamos o esquema a seguir, que ilustra essa ideia:

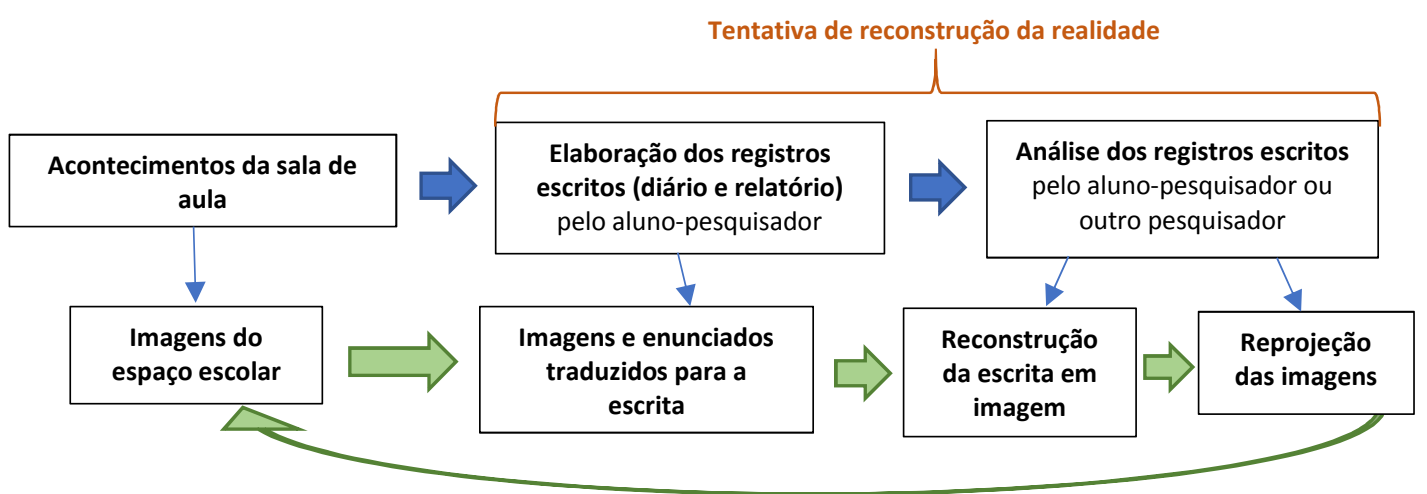

Figura 1: Construção da realidade por meio do registro escrito e de sua projeção visual (elaboração própria).

Quando falamos nessas imagens da sala de aula, podemos compará-las à fotografia ${ }^{8}$, pois o aluno-pesquisador joga luz sobre o que será destacado para o seu quadro, fazendo um recorte da realidade na qual está inserido, para a produção de sua técnica de escritura.

Ao dizer "recorte da realidade" e "jogar luz", invariavelmente nos vem à mente o trabalho de Cortázar (1974), em que ele compara o romance ao cinema, e o conto à fotografia. Cortázar (1974) procura descolar o cinema da fotografia sob o prisma de que a fotografia e o conto partem da noção de limite, acima de tudo no que toca ao lugar (limite físico), já um filme/romance têm uma ordem mais aberta.

No que toca aos registros escritos dos diários no estágio supervisionado, a fotografia e o cinema não são artes independentes, mas se complementam, tendo em vista que um filme é composto por inúmeros frames, os quais, por sua vez, são composições de muitas fotografias/fotogramas. Assim funciona o estágio supervisionado: sob uma perspectiva cinematográfica, o alunopesquisador capta em todo o diário de campo elementos parciais, acumulativos,

\footnotetext{
${ }^{8}$ Com essas "fotografias tiradas" pelo aluno-pesquisador, temos um conjunto de fotogramas, os quais podem tornar-se um filme. Para o presente trabalho, vamos focar as imagens sem elencálas à cinematografia.
} 
que não se excluem, de uma realidade ampla e multiforme do ambiente escolar; e sob um ponto de vista fotográfico, o aluno-pesquisador tem a necessidade de escolher e limitar uma imagem ou um acontecimento relevante, seja em sala de aula ou em outro ambiente escolar onde se dá a pesquisa.

Essa realidade ampla é composta por uma série de acontecimentos, os quais sofrem uma limitação prévia, imposta pela capacidade física e mnemônica do aluno-pesquisador e pela forma estética como o estagiário concebe essa limitação. Esse "corte" deve fomentar em seu leitor uma espécie de abertura, indo muito além do argumento escrito ou visual.

\begin{abstract}
Um fotógrafo profissional da categoria de um Cartier Bresson ou de um Brassi definem sua arte como um aparente paradoxo: o de recortar um fragmento da realidade, fixando-lhe determinados limites, mas de tal modo que esse recorte atue como uma explosão que abra de par em par uma realidade muito mais ampla, como uma visão dinâmica que transcende espiritualmente o campo abrangido pela câmara. (CORTÁZAR, 1974, p.151).
\end{abstract}

Tanto o trabalho de Calvino como o do aluno-pesquisador, ambos adaptam o "binóculo" (a lente da câmera e o olhar do pesquisador) à realidade observada e nós, leitores/pesquisadores, passamos a ver o mundo através do filtro de um "eu", neste caso Calvino, por meio de seus protagonistas nos contos, e os diários de estágio, por meio do aluno-pesquisador.

Tendo em vista os excertos apresentados (fragmentos 83 e 21), em um primeiro momento podemos pensar que os registros escritos possibilitam dar nova vida ao passado, assim como a fotografia. Vejamos a seguir trecho do conto "Aventura de um fotógrafo":

(...) somente quando põem os olhos nas fotos parecem tomar posse tangível do dia passado, somente então aquele riacho alpino, aquele jeito do menino com o baldinho, aquele reflexo de sol nas pernas da mulher adquirem a irrevogabilidade daquilo que já ocorreu e não pode mais ser posto em dúvida. O resto pode se afogar na sombra incerta da lembrança. (CALVINO, 1992, p.51) [grifo meu].

O excerto anterior, da obra de Calvino, expõe como a ação de olhar fotos torna tangível o passado. As imagens observadas no presente, as quais foram capturadas por uma lente no passado, partem de um cenário total - natureza álpica - o qual sofre três edições consecutivas - Edição 1: riacho em região 
montanhosa; Edição 2: menino brincando com baldinho; e Edição 3: reflexo do sol nas pernas de uma mulher. A esfera do cenário em sua totalidade e suas edições/seus recortes tornam palpáveis no fotograma o riacho, o menino, a mulher, o sol, entre outros detalhes em relação a esses agentes da foto.

Nos fragmentos 83 e 21, retirados do diário de observação, notamos como o real vivenciado pelo aluno-pesquisador foi transposto em registro escrito e este se faz vivífico no presente no momento da leitura por meio da menção dos interlocutores e da disposição das interações.

Percebemos, por meio dos fragmentos selecionados do diário e da citação anterior de Calvino, como essas escrituras são visuais/imagéticas em seus detalhes. Diante desse proêmio, observamos que os registros do alunopesquisador ao longo do estágio supervisionado parte da imagem, assim como os contos de Calvino. Assim, a partir do que foi apresentado até o momento, podemos refletir ao longo do presente trabalho sobre como o escritor e o alunopesquisador "pintam" as situações às quais são expostos.

No fragmento 83, o aluno-pesquisador traz em detalhes como estava ocorrendo a atividade sobre o poema de Paulo Leminski, as dúvidas que emergiram da turma, as interações e a tentativa de a professora fazer com que os estudantes compreendessem a diferença entre verso e estrofe. Importante destacar que para este evento o aluno colocou no diário o que estava anotado na lousa e a página do livro didático que constava o poema.

No fragmento 21, o aluno traz elementos interacionais e o objeto cerne da discussão, neste caso, o tablet. A forma como o registro escrito é construído possibilita que vejamos os agentes e o cenário da sala de aula como um todo acionando o nosso repertório social.

A partir dos dados e das descrições expostos até o momento, podemos traçar uma analogia entre o olhar do aluno-pesquisador e o do fotógrafo, por ambos fazerem um recorte do real ao tentar capturar um acontecimento, ou seja, esses olhares editam e reeditam o real, constituindo imagens que mostram a relação com esse real.

Antonino Piraggi faz recortes de imagens para fotografias, em especial, da figura de Bice; Calvino, por sua vez, traduz essas imagens e fotografias em 
texto escrito e o aluno-pesquisador, no estágio, traduz as imagens e enunciados da sala de aula em registro escrito (diário de campo e relatório de estágio), por meio da atenção, concentração, repertório social, capacidade mnemônica.

Para que pensemos nos enfoques, desfoques e recortes que o alunopesquisador faz, vejamos a figura abaixo, que ilustra hipoteticamente uma sala de aula.

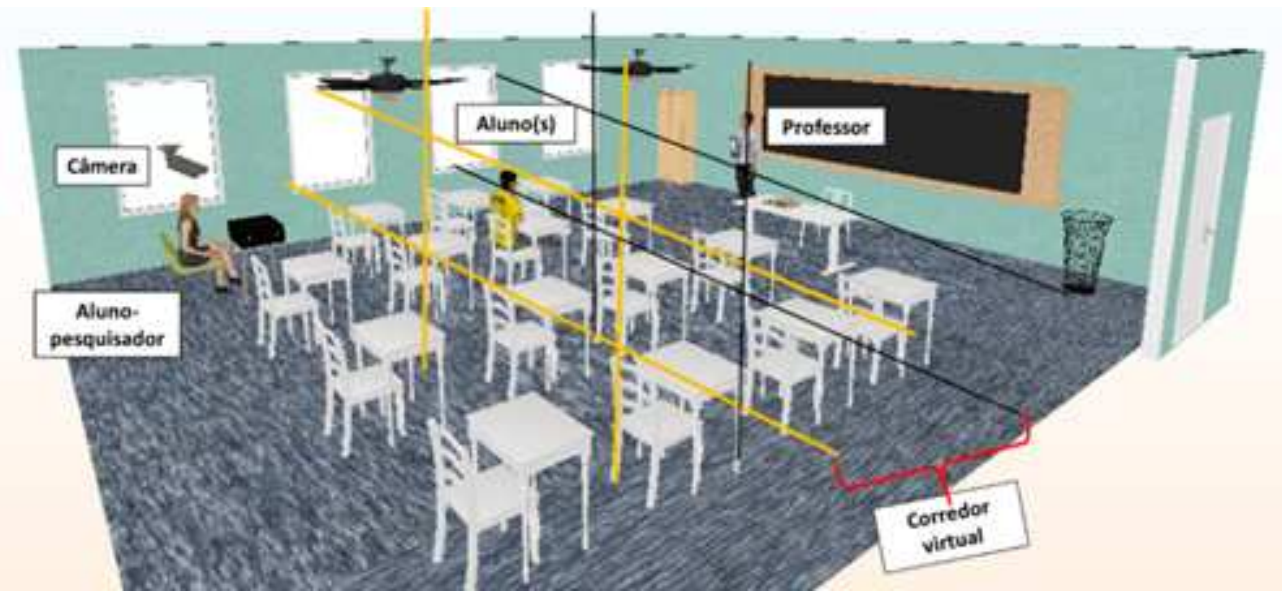

Figura 2: Aluno-pesquisador na sala de aula - corredor virtual (elaboração própria por meio do aplicativo Floorplanner).

Na figura 2, as linhas imaginárias estão em amarelo e preto e dividem a imagem em nove quadros (espécie de cerquilha), para representar os recortes que podem ser feitos para cada registro. Essas linhas imaginárias ajudam a visualizar o quadrante que o aluno-pesquisador pretende destacar, fazendo uso da regra dos terços 9 .

Feito esse posicionamento, verificamos o que será realçado e/ou cortado na imagem a ser registrada/ "fotografada". Posicionar quer dizer escolher um ponto de vista ou focar (estabelecer distância focal) o que se pretende registrar no diário; podemos relacioná-lo com a profundidade de campo da fotografia, ou seja, a porção de acontecimentos sobre a qual colocamos o foco, estabelecendo um corredor virtual perpendicular aos olhos.

\footnotetext{
${ }^{9}$ Técnica utilizada na fotografia para destacar algo na imagem e mantê-la equilibrada. Para isso, divide-se a fotografia em nove quadrados, traçando duas linhas horizontais e duas verticais (um "jogo da velha"), posicionando o assunto nos pontos de cruzamento ou em determinando quadrante.
} 
Ainda na figura 2, temos o aluno na região do corredor virtual e o professor em frente à porção em que o aluno está inserido. Diante dessa situação hipotética, o aluno-pesquisador, em seus registros no diário de campo, pode dar destaque a algo que o(s) aluno(s) está(ão) fazendo e/ou dizendo ou enfatizar a figura do professor. Isto é, o aluno-pesquisador "mexe o anel de foco da câmera", neste caso os próprios olhos e a consequente atenção mental, os quais alteram a distância do que se pretende focar e desfocar. Vejamos a imagem a seguir, que ilustra a interação entre aluno e professor quando o aluno-pesquisador altera o anel de foco da câmera, ou seja, os partícipes estão sob profundidades de campo diferentes:

Figura 3: Sala de aula em sua totalidade

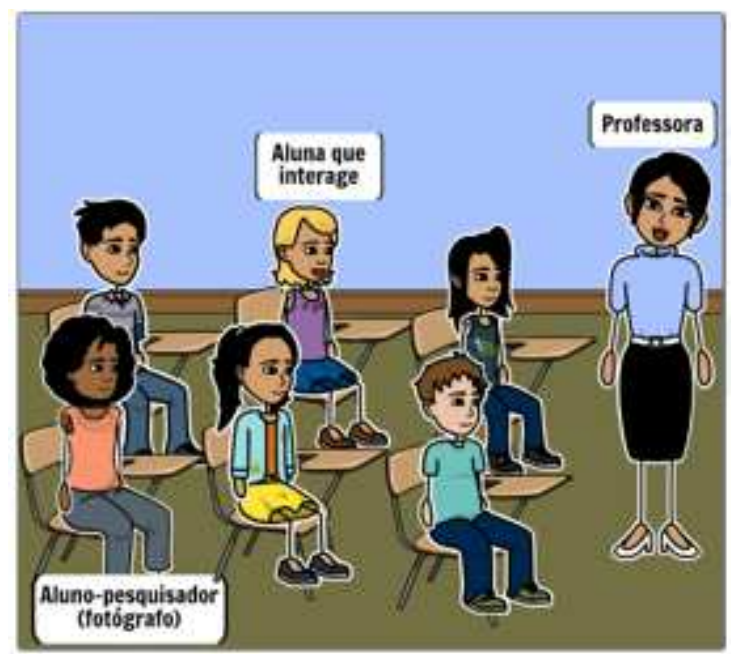

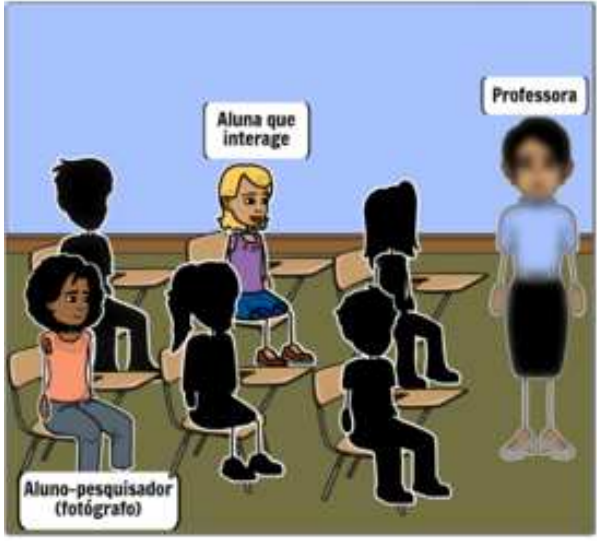

Figura 4: Foco na aluna

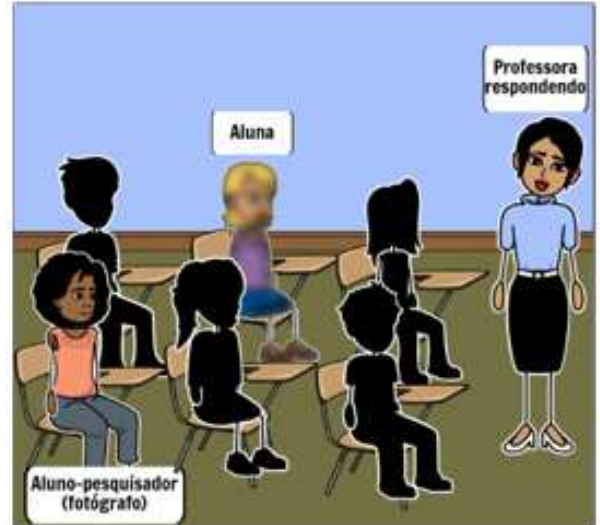

Figura 5: Foco na professora 
Tanto o aluno-pesquisador quanto Antonino Paraggi escolheram um ponto de vista eficiente, fornecendo um texto e uma imagem que impactem o seu leitor e espectador, a fim de trazer reflexões produtivas à pesquisa no ensino de língua materna, bem como as relações entre os partícipes, no primeiro caso, e particularidades do ver, no segundo.

A partir disso, refletimos sobre o que é fotografável com Antonino Paraggi, quando ele traz à baila a importância de reconhecer os acontecimentos e a ligação dos eventos para o registro na fotografia: "Se você fotografa Pierluca enquanto está fazendo o castelo de areia, não há razão para não fotografá-lo enquanto está chorando porque o castelo desmoronou, e depois enquanto a ama o consola fazendo-o encontrar no meio da areia uma casquinha de concha." (CALVINO, 1992, p.54).

É este mesmo procedimento que ocorre quando se está na posição de observador na sala de aula: enxerga-se a cena como um todo, já com algumas perdas, e, a partir desta certa totalidade/realidade, destacamos o que se deseja trazer para o leitor.

Por exemplo, nos fragmentos 83 e 21 , temos uma cena ampla/total, que é a sala de aula com alunos e professores executando ações variadas; e, nesses dois fragmentos, o aluno-pesquisador fez um recorte/uma edição da cena ampliada.

No fragmento $83^{10}$, a partir da cena ampliada, foi fotografada a interação professor-aluno, tomando como mote a atividade sobre poesia. Considerandose o excerto, percebemos que o anel de foco do aluno-pesquisador, ao fazer 0 recorte, alterna entre Professora - Classe - Professora - Classe - Professora Aluna específica - Professora.

Dentro do recorte sobre o que é estrofe e verso na classe há um subrecorte dentro dessa temática, no caso o enfoque entre a aluna e a professora. Desta forma temos o seguinte plano de edição para a situação em questão: Cenário total - Sala de aula; Edição 1: Sala de aula e professora (campo mais

\footnotetext{
${ }^{10}$ A partir dessas interações, podemos obter um storyboard do fragmento 83, a fim de visualizar a fotografia para cada evento, por meio de fotogramas. Vide anexos 1.
} 
aberto, interação entre professora e sala); Edição 2: Aluna e professora (a partir do campo aberto, tem-se um recorte dentro do corte principal).

No fragmento $21^{11}$, também a partir da cena ampla da sala de aula, temse a interação aluno-professor, em virtude de um evento corriqueiro pertinente ao dia a dia escolar, a chamada; neste episódio, o aluno-pesquisador maneja o anel de foco entre Aluno1 - Aluno2 - Professora - Aluno1, perfazendo dois recortes dentro do uma cena pequena escolhida a partir do cenário total: Edição 1: aluno e aluna (temos um campo mais restrito em relação a toda a sala de aula, o qual sofre alternância para outros agentes); Edição 2: Professora e alunos.

A partir do cenário total, percebemos que o fotógrafo faz diferentes recortes, destacando diferentes eventos dentro da cena. Tendo em vista a alternância de distanciamento focal, notamos que o percurso descrito acima mostra que, segundo Blikstein (2018, p.48), a língua não recorta a realidade propriamente, mas o referente ou a realidade fabricada. A percepção do que captamos como realidade não é ingênua e está condicionada a um sistema de crenças cristalizadas e a uma construção e prática social.

Blikstein (2018, p.62-63) nos traz um quadro de Magritte, La condition humaine (1935), para demonstrar que não enxergamos o "real", mas o referente, ou o real fabricado. O mesmo acontece quando o aluno-pesquisador, imerso no universo desordenado da sala de aula, capta determinados eventos, os quais podem ser vistos nos storyboards dos fragmentos nos anexos 1 e 2 , ou mesmo Antonino Paraggi, que faz recortes sobre o que será fotografado, quando escolhe o que será captado ao registrar as moças jogando bola na praia.

(...) Antonino saltitava no mar em volta das duas amigas para pôr em foco os movimentos do jogo e excluir do enquadramento os reflexos ofuscantes do sol na água. Numa disputa pela bola de Bice, que se lançava sobre a outra já submersa, foi apanhada com o traseiro em primeiro plano voando por sobre as ondas, Antonino, para não perder esse ângulo, jogara-se na água de través mantendo a máquina erguida e por pouco não se afogara. (CALVINO, 1992, p.56).

Com base na demonstração de alternância de foco dentro da sala de aula sob a perspectiva do zoom óptico do aluno-pesquisador, neste caso comparado

\footnotetext{
11 A partir dessas interações, podemos obter um storyboard do fragmento 21 , a fim de visualizar a fotografia para cada evento, por meio de fotogramas. Vide anexos 2.
} 
a um fotógrafo ${ }^{12}$, e com base nas contribuições de Blikstein (2018), no que se refere à percepção da realidade e do referente, verificamos que, por meio desses recortes (ou enfoque do olhar), torna-se discernível na primeira passagem (fragmento 83) o destaque do aluno-pesquisador à tentativa de a professora engajar todos os alunos na aula para solucionar determinada dificuldade da turma (a distinção entre estrofe e verso); ela consegue a participação dos alunos, porém não obtém respostas que atendam as expectativas de suas perguntas. Aqui temos um novo enfoque, agora nos alunos. Os enfoques alternam entre professora e turma, até o momento em que temos o foco em uma aluna específica, culminando na ratificação negativa dessa aluna. O último enunciado, "Obrigação de quem falta é pegar a matéria!", pode servir tanto para a aluna específica como para toda a turma.

Observa-se que o fragmento 83 do diário de observação seguiu a estrutura de troca de turnos. Segundo estudos de Sinclair e Coulthard (1975), a troca de turnos é uma estrutura que se revelava recorrente no ambiente de sala de aula. Essa estrutura acontece por meio da iniciação-resposta-avaliação (IRA), na qual a "iniciação" é a pergunta-teste com que, por meio de resposta conhecida, o professor visa avaliar o aluno/a turma.

Os estudos de Sinclair e Coulthard (1975) revelaram que se trata de uma estrutura dificilmente encontrada em conversa rotineira, uma vez que ela arroga um status interacional superior ao iniciador, o que caracteriza uma assimetria entre os participantes da interação. Essa superioridade é legitimada por meio do papel institucional representado pelo professor.

Já o fragmento 21 do diário do estagiário, por meio do enfoque do olhar, torna-se discernível que o aluno-pesquisador deu destaque a uma interação envolvendo dois alunos e a professora, ou seja, o enquadramento da fotografia fica reduzido em relação a todo o cenário de sala de aula. A alternância do distanciamento focal ocorre apenas entre esses dois alunos e a professora, e é escolhido a partir de uma conversa que leva em consideração assuntos de ordem social e ética.

${ }^{12}$ Os storyboards (Anexos 1 e 2) auxiliam na visualização da alternância de foco. 
O diálogo, no excerto 21, tem início com a curiosidade de um determinado aluno em saber se o tablet poderia ser levado para casa, dado que ele parece entender que o objeto é da escola, uma vez que a professora o utiliza para fazer chamada, fazer lançamento de notas e registrar as atividades realizadas. Nesse primeiro enfoque no aluno que faz a pergunta, podemos imaginar que ele pensou que a professora teria a possibilidade de utilizá-lo para fins pessoais (acessar o e-mail, as redes sociais, notícias, etc.). Entretanto, a professora não tem tempo hábil de responder a essa pergunta, quando um outro aluno interfere expondo 0 que faria com o objeto, desenhando um novo foco. $O$ enfoque volta para a professora, que explica as consequências de roubar o tablet e em seguida temos o enfoque de volta ao aluno que iniciou a interação, justificando por que "valeria a pena" ficar com o aparelho. Esses enfoques que atravessam a aula, se constituem a partir das interações que ocorrem (interação verbal ou paraverbal por meio da alternância entre os sujeitos) e eventos eleitos relevantes para o aluno-pesquisador.

Neste embate, o aluno-pesquisador/fotógrafo observa e destaca a curiosidade dos alunos e estes, a seu tempo, sugerem o que fariam e como "sairiam no lucro"; isto, na verdade, mostra-se o mais absolutamente falso e irracional lucro: perder sua liberdade por causa de um tablet.

A partir dessa analogia pesquisador-fotógrafo, o pesquisador, dependendo do acontecimento, pode destacar o enunciado do aluno e, depois, o do professor ou vice-versa. Enfim, o observador maneja o seu olhar para os acontecimentos que presume serem significativos para constar no diário de estágio. Assim, o papel do estagiário ao registrar vai ao encontro das funções da fotografia, a qual busca mostrar o que é sério, importante, falso, forçado. Calvino (1992) nos possibilita refletir sobre essas facetas da fotografia, passíveis de serem decalcadas nos registros de estágio.

Uma fotografia oficial ou matrimonial ou familiar ou escolar dava sentido do quanto cada papel ou instituição tinha em si de sério e importante, mas também de falso e forçado, de autoritário, hierárquico. Este é o ponto: tornar explícitas as relações com o mundo que cada um de nós traz consigo (...) (CALVINO, 1992, p.57). 
Devem-se ter em vista, na observação das aulas, as ponderações sobre o espaço discursivo, no qual o observador está inserido, de modo que seja feito os devidos focos e desfoques, enquadramentos, recortes e sub-cortes dos enunciados produzidos em sala de aula por professor, alunos, funcionários e até mesmo pelo próprio aluno-pesquisador, caso ele interaja ativamente.

Transpor ao texto escrito e visual o que foi registrado e fotografado pode tornar-se complicado, contudo, os detalhes enriquecem o trabalho, tanto do aluno-pesquisador, quando traz particularidades da sala de aula, quanto de Antonino Paraggi, quando dá detalhes de Bice para tornar-se tema fotográfico:

Só com um vestido de noite Bice se tornaria um tema fotográfico, com o decote que assinala uma fronteira nítida entre o branco da pele e o escuro do tecido sublinhado pelo reluzir das jóias, uma fronteira entre uma essência de mulher atemporal e quase impessoal em sua nudez e a outra abstração, esta social, do vestido, símbolo de um papel igualmente impessoal, como o drapeado de uma estátua alegórica. (CALVINO, 1992, p.60).

Os detalhes presentes no conto sobre como Bice é e pode ser retratada na fotografia chega a ser classificada pelos amigos e por ela também como obsessão, porém Antonino Paraggi diz que se trata de "uma questão de método" (CALVINO, 1992, p.62). Nessa fala da personagem, temos um lado otimista de Calvino, segundo o qual é possível chegar a um modelo.

Desse modo, ao fotografar, esgotando todas as imagens possíveis, bem como ao registrar o maior número de eventos no diário de estágio, obtém-se uma imagem mais próxima do real, que pode arrematar o leitor ou o espectador. Para além dos momentos interacionais, o aluno pesquisador pode trazer para seu leitor as atividades desenvolvidas em sala de aula, assim o leitor poderá verificar como o docente e discente lidam com o objeto de estudo eleito na(s) aula(s) observada(s), assim o leitor pode acompanhar o que é ensinado e o próprio desenvolvimento dos alunos em relação às atividades. Todos esses elementos possibilitam uma visão holística da sala de aula, seja das relações humanas ou do ensino, possibilitando traçar novas ações/práticas que vislumbrem inovações no ambiente de ensino.

De acordo com Calvino (1992, p.54), viver de um modo o mais fotografável possível, ou então considerar fotografáveis todos os momentos da própria vida 
nos direciona para dois caminhos, o primeiro nos leva à estupidez e o segundo à loucura, o que exige que aprendamos a ver e, consequentemente, a registrar o que é necessário, assim como Amilcare Carruga o fez ao usar seus óculos novos: "Teve que se acostumar pouco a pouco, aprender desde o começo o que era inútil olhar e o que era necessário." (CALVINO, 1992, p.98).

Destarte, chegamos ao objetivo de Antonino Paraggi, que visava “... um retrato todo em superfície, patente, unívoco, que não se furtasse à aparência convencional, estereotipada, à máscara." (CALVINO, 1992, p.58). Dessa maneira, podemos pensar sobre o que queremos mostrar na superfície, no plano médio e na profundeza do texto, de modo que em um único recorte possamos atingir todas essas superfícies para a construção da imagem: "Havia muitas fotografias possíveis de Bice e muitas Bices impossíveis de fotografar, mas aquilo que ele buscava era a fotografia única, que contivesse tanto umas quanto outras." (CALVINO, 1992, p.58).

Por fim, ao registrar e fotografar eventos pelos quais se pretende eternizar os acontecimentos para oportunidade futura, aprendemos a gerenciar o nosso olhar. Nos registros em sala de aula, é possível comparar o olhar do alunopesquisador ao de Amilcare Carruga, no sentido de que, no início do estágio supervisionado, o aluno-pesquisador pode enxergar os acontecimentos com entusiasmo diante do novo, mas depois esse ânimo se esvai.

(...) reparou que de uns tempos para cá essa vida para ele andava, imperceptivelmente, perdendo o gosto. (...) Antigamente as cidades novas o exaltavam (...) agora só percebia nelas o aborrecimento, a confusão, a desorientação. (...) até o cinema, para, todas essas caras Ihe pareciam ter se tornado desbotadas, sem relevo, anônimas; entediava-se. (CALVINO, 1992, p.97).

É fundamental que o olhar do aluno-pesquisador no percurso do estágio não esmoreça diante dos inúmeros acontecimentos (dados) que passam diante de seus olhos; são esses dados que serão transformados em registros escritos e visuais. Assim, manter o entusiasmo com objetividade e concentração colabora para que, a cada dia vivido ao longo do estágio supervisionado, o alunopesquisador enxergue com ineditismo os acontecimentos e, portanto, esforce-se por coletar o maior número possível de enunciados e imagens, deixando de ser 
míope como Amilcare Carruga: "Por fim, entendeu. Estava míope. O oculista the receitou um par de óculos. A partir daquele momento sua vida mudou, tornou-se cem vezes mais rica em interesse do que antes." (CALVINO, 1992, p.98).

\section{CONSIDERAÇÕES FINAIS}

Este trabalho buscou pensar sobre o registro escrito feito pelo alunopesquisador (estagiário) durante o estágio supervisionado sob uma perspectiva imagética; e como as ideias de Calvino (1992) presentes nos contos "A aventura de um fotógrafo" e "A aventura de um míope", da obra "Os amores difíceis", possibilitaram refletir sobre como a escrita parte de uma imagem e como esses escritos podem reprojetar a imagem inicial/experiência vivenciada.

O fato de os dois contos meditarem sobre o "ver" permite estabelecer uma analogia escolar, no caso, com os registros coletados no diário de observação. Estes registros, por sua vez, se interseccionam diretamente com a temática dos contos, seja na perspectiva da fotografia ou da miopia. A fotografia abrange 0 tempo-realidade/tempo-espaço, apesar dos limites de registro (limitações físicas e mnemônicas do aluno-pesquisador), e capta um instante real, ao passo que o problema de enxergar a realidade faz com que observemos os acontecimentos sem entusiasmo, exigindo que tomemos uma atitude proativa para passarmos a ver a realidade em que estamos inseridos de forma a ver novidades sempre; é claro que esse olhar passa a ser manejado pelo aluno-pesquisador, o qual analisa o que pode ou não ser recortado da realidade como Amilcare Carruga.

Calvino buscou fusão entre linguagem científica e humanística, procurando os pontos de contato. Assim, escritura é um instrumento analítico, e ela expressa enorme complexidade do real. Pode-se pensar que, em Calvino, a escrita é uma explicação da imagem, mas não é isso; trata-se de traduzir as imagens no escrito, em que no centro do discurso visual há um "eu".

Quando começamos a escrever, a escrita segue uma lógica que difere de uma a outra pessoa, o que faz refletir sobre a técnica de escritura que o alunopesquisador utiliza para recortar/fotografar, partindo da jornada de Antonino Paraggi e das contribuições de Cortázar (1974). 
Neste processo que une a imagem e a escritura e vice-versa, o detalhe é essencial e complexo, todavia, apesar das adversidades, 0 pesquisador/fotógrafo pode se valer de sensibilidade, não no sentido romântico que a palavra evoca, mas sim no de empatia, que possibilita ultrapassar a coleta do tão-somente óbvio, do aparente.

Apesar de os homens serem incapazes de apresentar várias coisas ao mesmo tempo em seu discurso, quando a sensibilidade é acionada é possível haver uma semiose pré-verbal ou paraverbal, as quais conduzem para a elaboração de um "pensamento visual" em relação aos eventos que se julguem relevantes trazer para o registro escrito, para neles se aprofundar.

O aluno-pesquisador que realiza o registro do maior número de detalhes do que é observado, não o faz visando mostrar imagens propositalmente (em alguns casos, a depender do repertório, pode ser o intuito), o objetivo maior é explanar de modo detalhado o cenário escolar (relações entre partícipes e relação com o ensino). Nossa proposta no presente estudo é mostrar que podemos transpor o registro em imagem, além disso o fato de não conseguir "fotografar" tudo, não invalida o acontecimento.

A partir de registro com maior informatividade é possível perceber o processo imagético que emerge da escritura e neste momento percebemos como a imagem e a escrita entram em convergência, por conseguinte, a realidade vivenciada pode ser transposta em imagens para o leitor do diário ou do relatório.

A partir da análise dos fragmentos 83 e 21, com o auxílio dos dois contos de Calvino, foi possível constatar que a linguagem perpassa diferentes pontos de nossa existência e se manifesta de diferentes formas, uma vez que é pela linguagem que entendemos e criamos o nosso mundo, (re)ordenado de diferentes maneiras possíveis. Ao final deste percurso investigativo, constatamos algumas premissas: a) é possível estabelecer pontes entre 0 cenário escolar (por meio do estágio) e o mundo da arte literária; b) a fotografia/imagem, posto que é linguagem, é uma criação de quem fotografa e de quem a lê; c) é possível verificarmos a projeção dos registros de sala de aula em imagens, de modo a se habitar o mundo escrito e o não-escrito. 


\section{REFERÊNCIAS}

BLIKSTEIN, I. Kaspar Houser ou a fabricação da realidade. São Paulo: Contexto, 2018.

CALVINO, I. A aventura de um fotógrafo In: CALVINO, I. Os amores difíceis. São Paulo: Companhia das Letras, 1992. p. 51-64.

CALVINO, I. A aventura de um míope. In: CALVINO, I. Os amores difíceis. São Paulo: Companhia das Letras, 1992. p. 97-106.

CORTÁZAR, J. Alguns aspectos do conto. In: CORTAZAR, J. Valise de Crosópio. São Paulo: Perspectiva, 1974. p. 149-163.

NUNES, B. O tempo na narrativa. São Paulo: Ática, 2000.

SINCLAIR, J.; COULTHARD, M. Towards an analysis of discurse. Londres: Oxford University Press, 1975.

StoryboardThat @2021. Disponível em: www.storyboardthat.com Acesso em: 29/10/2021.

Floorplanner @2021. Disponível em: www.floorplanner.com Acesso em: 29/10/2021. 


\section{Anexos}

\section{Anexo 1 (Fragmento 83)}
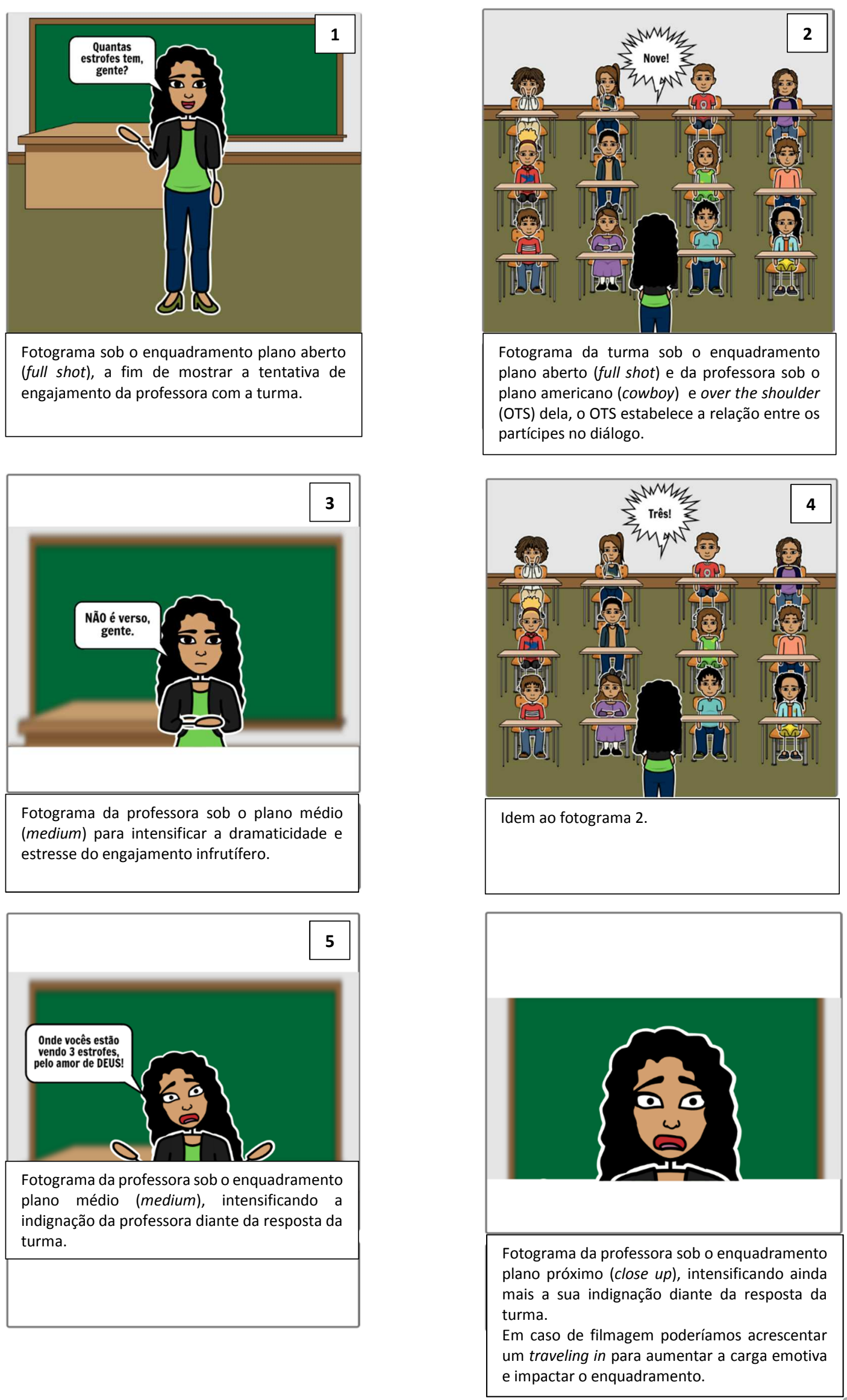

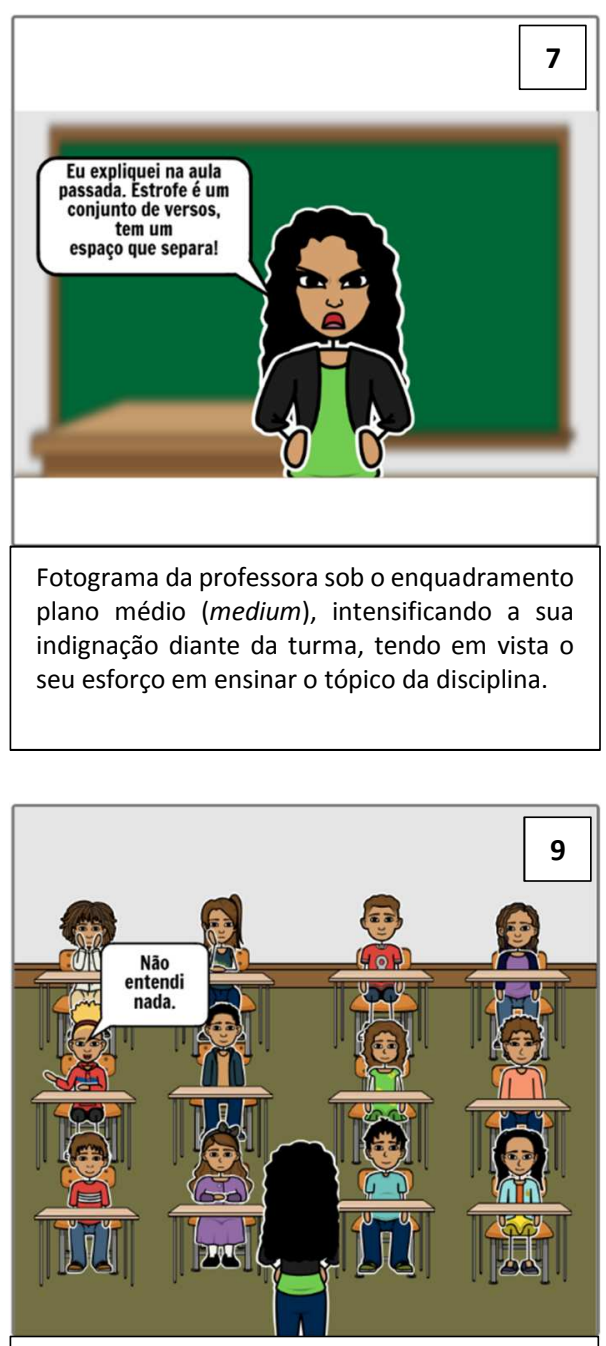

Idem ao fotograma 2.

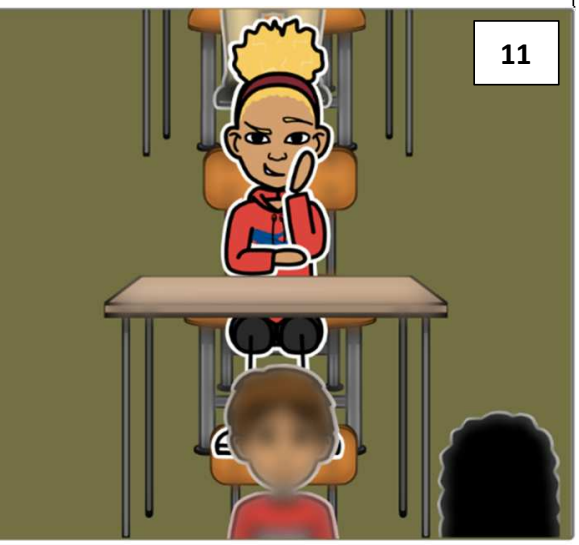

Fotograma da aluna que se manifestou sob um plano individual (PI), que tanto vale para a perspectiva do fotógrafo quanto para a perspectiva da professora, que está nesta foto desfocada.
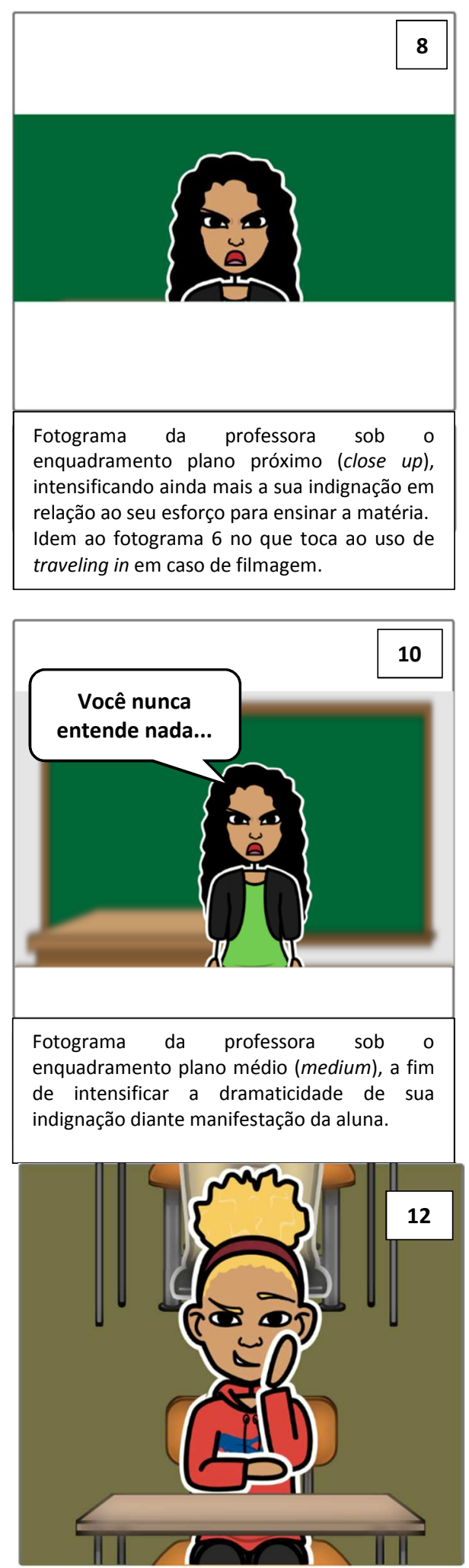

Fotograma da aluna que se manifestou sob um plano individual (PI) e com pequeno zoom para intensificar o estresse da situação e o tom desafiador da aluna. 

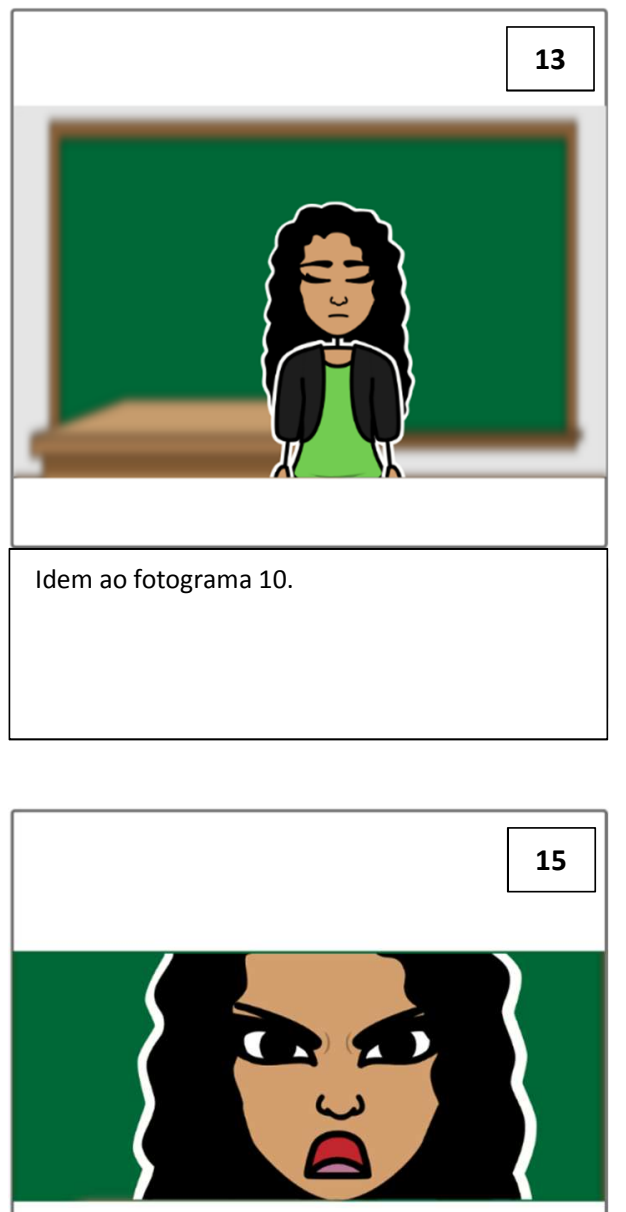

Fotograma da professora sob o enquadramento extreme close, intensificando ainda mais a dramaticidade dos quadros anteriores.

Idem ao fotograma 6 no que toca ao uso de traveling in em caso de filmagem.

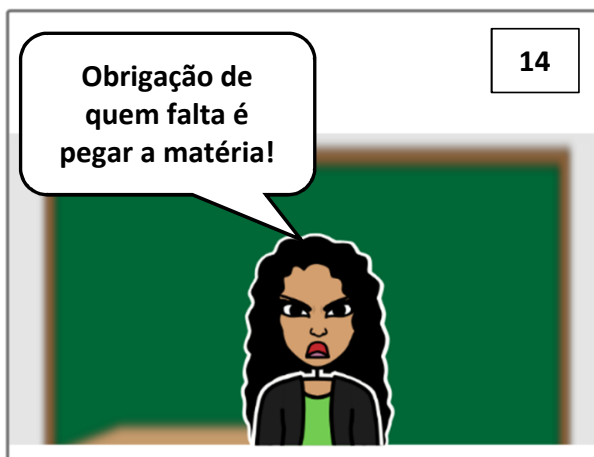

Fotograma da professora sob o enquadramento $2 \mathrm{~T}$, a fim de intensificar a dramaticidade de sua indignação diante da manifestação da aluna e do não entendimento da turma em relação a matéria.

A fotografia sendo tirada sob o ângulo contra plongée intensifica ainda mais a tensão estabelecida, bem como delineia a relação de poder entre professor e aluno.

Idem ao fotograma 6 no que toca ao uso de traveling in em caso de filmagem.

\section{Anexo 2 (Fragmento 21)}
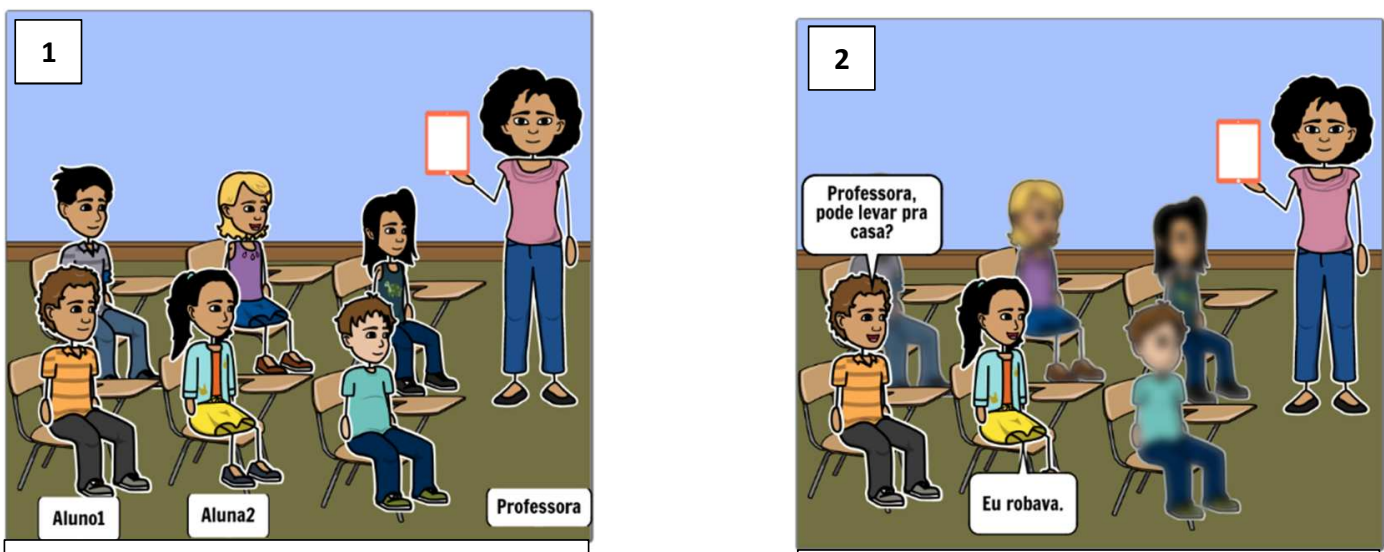

Fotograma da turma sob o enquadramento plano aberto (full shot).

Fotograma da turma sob o enquadramento plano aberto (full shot), desfocando os alunos que não participam da interação. 

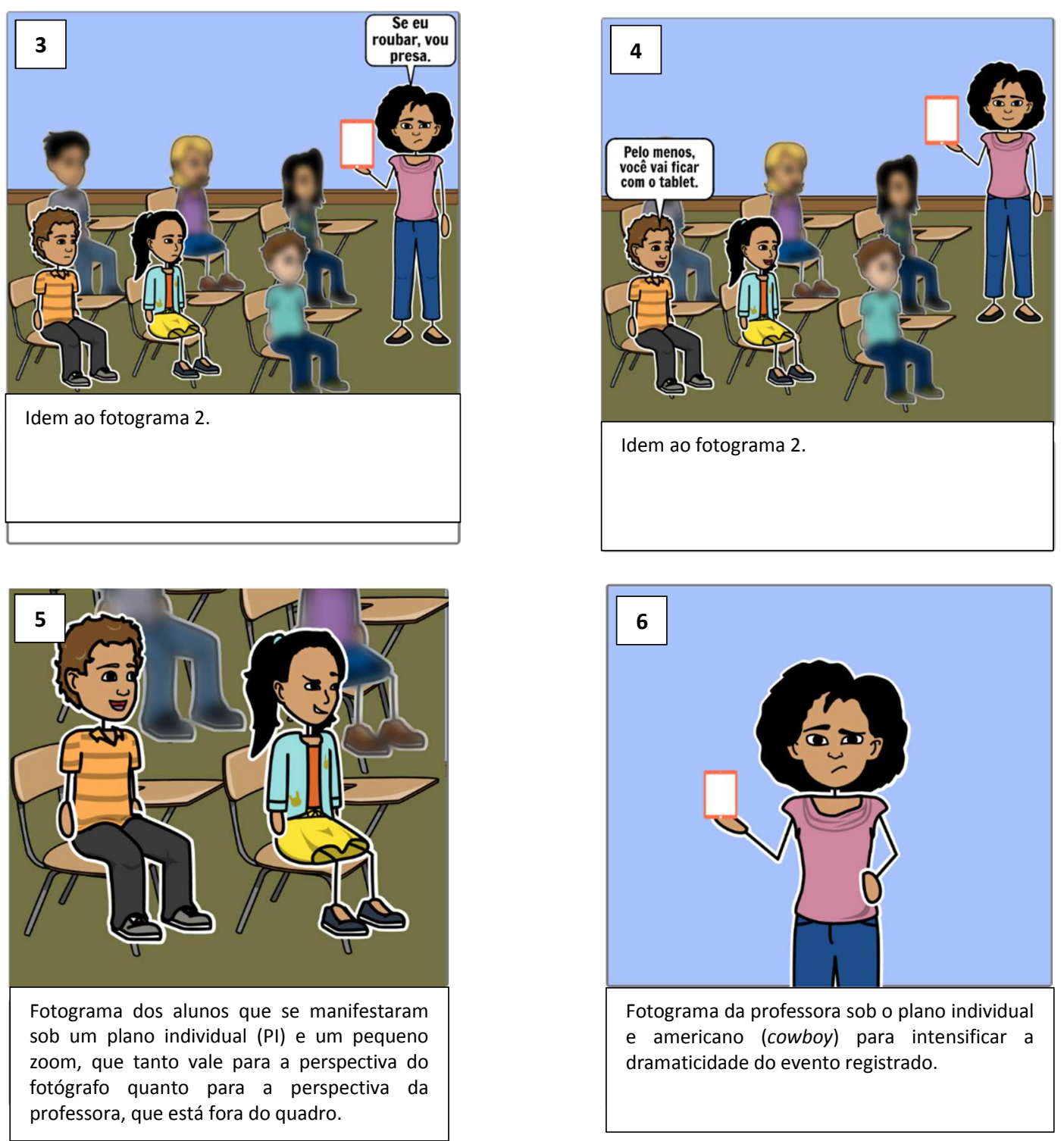


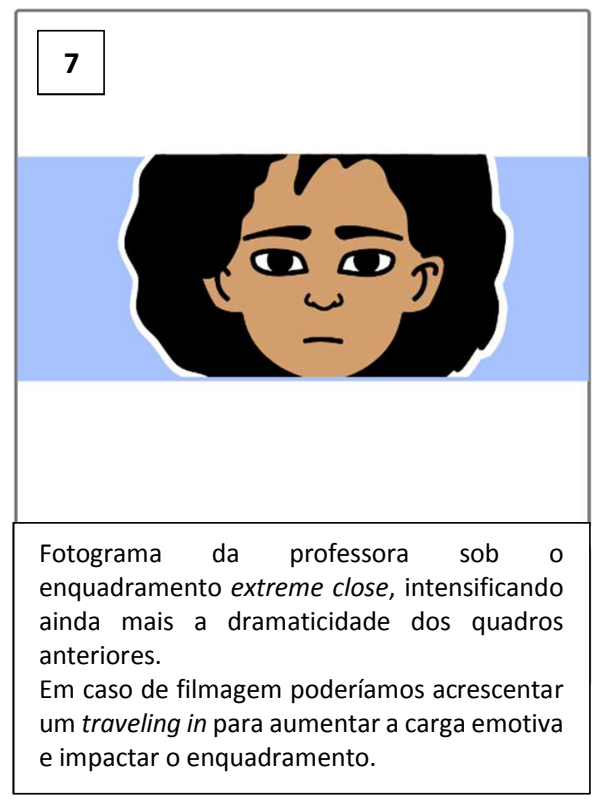

